\title{
Analysis of community attributes of the benthic macrofauna of Frierfjord/Langesundfjord and in a mesocosm experiment
}

\author{
J. S. Gray ${ }^{1}$, M. Aschan ${ }^{1, *}$, M. R. Carr ${ }^{2}$, K. R. Clarke ${ }^{2}$, R. H. Green ${ }^{3}$, T. H. Pearson ${ }^{4}$, \\ R. Rosenberg ${ }^{5}$, R. M. Warwick ${ }^{2}$ \\ ${ }^{1}$ Department of Marine Zoology and Marine Chemistry, Biology Institute, University of Oslo, PO Box 1064, N-0316 Blindern, \\ Oslo 3, Norway \\ ${ }^{2}$ Plymouth Marine Laboratory (West Hoe), Prospect Place, The Hoe, Plymouth PL1 3DH, United Kingdom \\ ${ }^{3}$ Department of Zoology, University of Western Ontario, London, Ontario, Canada N6A 5 B7 \\ ${ }^{4}$ Scottish Marine Biological Association, Dunstaffnage Marine Research Laboratory, PO Box 3, Oban, Argyll PA34 4AD, \\ Scotland, United Kingdom \\ ${ }^{5}$ Department of Zoology, University of Göteborg, Kristineberg Marine Biological Station, Fiskebäckskil, Sweden
}

\begin{abstract}
Sublittoral macrofauna was sampled along a putative pollution gradient at 6 sites in Frierfjord/Langesundfjord, Norway, during the GEEP Workshop. Data were subjected to a variety of multivariate statistical analyses which discriminate between sites on their faunistic attributes, and univariate measures of community stress were determined. Multivariate analyses produced generally similar results. Univariate stress measures in combination ranked the sites in order of increasing disturbance. Measured levels of pollutants in the sediments correlated poorly with the multivariate 2-D configurations and with the univariate measures of disturbance. It was concluded that water depth was the overriding factor controlling community structure, and that this masked any possible effects of pollution. The 3 deepest sites displayed the most obvious signs of stress, and this was attributed to seasonal anoxia in the deeper parts of Langesundfjord. In order to establish cause and effect relations between measured levels of pollutants (copper and hydrocarbons) and community responses, boxcores of sublittoral sediment were subjected to 4 levels of contamination in a mesocosm experiment. Although some of the 'classical' intuitive methods indicated possible community responses, the objective methods largely failed to reveal clear-cut differences in community structure between treatment levels. The relative merits of the 'classical' and objective approaches are discussed
\end{abstract}

\section{INTRODUCTION}

Along a gradient of pollution it is generally believed that there will be a changing pattern of species abundances as each species will have a different level of response to the pollutant. Species living in sediments must, in response to the pollutant move, tolerate it or die. In a given community the most frequent response is that some species increase in abundance, many decrease in abundance and others remain unaffected. The patterns of species abundances found will reflect effects of the pollutant integrated over time, and are therefore widely used to monitor effects of pollutants in subtidal sediments.

- Present address: Biology Institute, University of Tromso, N-9000 Tromse, Norway
Traditionally, macrofauna have been used for pollution monitoring, but increasing attention is being given to meiofauna, whereas microfauna have scarcely been used at all. The arguments for using meiofauna are given by Heip et al. (1988), but the macrofauna are currently most widely used because taxonomic expertise is generally more available for such organisms compared with the meio- and microfauna, and more is known of the general biology of species. Moreover, their relative longevity, with many species having lifespans in excess of $2 \mathrm{yr}$, allows the macrofauna to integrate responses to environmental pressures over extended time periods, thus enhancing their utility in time series analyses of pollution effects. The practical advantages of handling larger, mainly sedentary, organisms both for enumeration in the field and in experimental situations have also increased the 
emphasis on macrobenthic community analyses to assess the impact of environmental disturbance on marine areas. This has in turn resulted in the development of a wide range of analytical techniques for macrobenthic studies.

A wide range of these techniques was used to compare responses of the macrofauna to mixed pollution gradients in the field and in experimental mesocosms. Whilst not all proposed techniques were examined at the GEEP Workshop, a selection of those most commonly used were assessed, together with some of those most recently suggested. They ranged from simple statistics - such as species number, abundance and biomass - to descriptions of patterns of abundance and biomass among species, a range of multivariate analytical techniques, and identification of indicator species or higher taxa. The results of the analyses were discussed in plenary sessions and a common consensus of the interpretation of the results is presented.

\section{METHODS}

Field sampling methods and details of the mesocosm experiment are given elsewhere (Bakke et al. 1988, Follum \& Moe 1988). In summary, for the field study, seven $0.1 \mathrm{~m}^{2}$ Day grab samples were taken for macrofauna at Sites $A, B, C, D, E$ and $G$, sieved at $1.0 \mathrm{~mm}$ and preserved in formalin. Only 4 replicates from each site were analysed. For the mesocosm experiment, twenty $0.25 \mathrm{~m}^{2}$ USNEL box-core samples were taken from Bjørnhodet Bay and transferred undisturbed in plastic liners to the 4 mesocosm basins, 5 being allocated at random to each treatment level. At the end of the experiment, two $9.3 \mathrm{~cm}$ diameter cores were taken from 4 of the 5 boxes in each basin and processed as above. The remaining contents of each box were sieved at $5.0 \mathrm{~mm}$ and preserved to provide a second data set which included large macrofauna not sampled in the cores. Large organisms present in these latter samples were identified to species level, but smaller taxa were identified only to genus, family or group. For the main sets of samples from both field and mesocosm studies, the macrofauna were identified, and weighed wet, by one of us (M.A.) save for polychaetes which were identified by B. Rygg (Norwegian Institute for Water Research, NIVA). Subsequent data analysis consisted of 3 categories of techniques, as follows.

Multivariate analyses. For both species abundance and biomass arrays, triangular matrices were computed of similarities between every pair of samples, using the Bray-Curtis coefficient (Bray \& Curtis 1957). Prior to this computation, the data were subjected to a number of transformations of increasing severity. These ranged from no transformation (for which a few species dominate the between-sample similarities), through $, x_{1}, x$ and $\log (1+x)$ to presence/absence (which weights rare species as heavily as more common species). These similarity matrices were then subjected to both clustering and ordination analyses. Clustering was by an hierarchical, agglomerative method employing group-average linking, the results of which are displayed in a dendrogram (e.g. Everitt 1974). Ordination was by non-metric multi-dimensional scaling (MDS), e.g. Kruskal \& Wish (1978). This attempts to construct a 'map' of the sites in which the more similar 2 samples are in terms of species abundances (or biomass) the nearer they are to each other on the 'map' The extent to which the relations can be adequately represented in a 2 (rather than 3 or higher) dimensional map is summarized by a 'stress coefficient', MDS is perhaps the most robust ordination technique available, using only rank order information of the form Sample 1 is more similar to Sample 2 than it is to Sample 3'. It follows that configurations will have arbitrary orientation and scale.

These multivariate techniques do not use the known allocation of the replicate samples to sites. The first step in interpretation was therefore to examine the plots and dendrograms for evidence that replicate samples within sites are 'closer together' than samples from different sites. Formal significance tests that there were no differences between all sites (or between selected sets of sites) were performed using the ANOSIM randomization test described in Clarke \& Green (1988). MDS analyses were also repeated separately within any major group of sites seen in the original plot, thus allowing the fine structure of a group to be accurately displayed. (The stress coefficient is dominated by large dissimilarities so that, for an MDS of all sites, the algorithm concentrates mainly on relative placing of the major groups rather than structure within groups.)

Ordination techniques not based on Bray-Curtis similarities were also employed, though for a more limited set of the data arrays and transformations. These included Reciprocal Averaging (RA, Hill 1973) and Detrended Correspondence Analysis (DECORANA, Hill \& Gauch 1980).

For the mesocosm data, in addition to the above analyses, 'classical' multivariate techniques were applied. The assumptions underlying these correlationbased methods require that the less common species be omitted; a subset of species was chosen using the criterion that species retained should have $3 \%$ or more of the numbers of individuals in all species, in one or more of the 16 replicates (Field et al. 1982). This produced a subset of 20 species from the initial set of 71 . An among-species correlation matrix was calculated based on $\log (1+x)$ transformed data. A Principal Components Analysis (PCA, e.g. Harris 1975, Pimentel 
1979, Seber 1984) was carried out on this correlation matrix. A plot of PC2 versus PC1 scores with the 16 replicates labellod by treatment level ( 4 replicates for each of 4 treatment levels) was created, and significance of differences in PC1 and PC2 scores among treatment levels was determined by 1 -way analysis of variance (ANOVA). Because 2 ANOVAs were done in each case, without knowing beforehand whether any among treatment level differences might occur in PC1 or PC2, Bonferroni's correction (Seber 1984) was used (i.e. significance at 0.025 was required in each of the 2 tests). Next a multivariate analysis of variance (MANOVA) was used to test treatment level differences in species composition. (For discussion of MANOVA see Harris 1975, Pimentel 1979, Seber 1984.) However, such a test cannot be done with 20 variables, given that there are 4 treatment levels with 4 replicates per level; there would be no degrees of freedom remaining. Five variables would permit an F-test of Roy's Greatest Root criterion (Roy 1953, Pillai 1967, Seber 1984). The 5 variables used were the first 5 principal components (PC1PC5), which accounted for $72 \%$ of the total variance (in the 20-variable data array). Use of Roy's Greatest Root criterion assumes (plausibly in this situation where there is one superimposed pollution gradient) that there will be one significant among-treatment level gradient, or none. A test with 10 error d.f. should be robust to moderate violations of assumptions in ANOVA (e.g. non-normality, heterogeneity of variance). If the $F$-test is significant then the order of the treatment means on the first canonical variate (CV1) is compared with the order of severity of the treatments.

Further details of clustering and ordination techniques, associated hypothesis tests and the effects of transformations are given in Clarke \& Green (1988).

Descriptive statistics. Descriptive measures computed were the number of species per sample (S), abundance of individuals (A) and biomass (B), plotted over samples following Pearson \& Rosenberg (1978). The ratios $B / A$ and $A / S$ (Pearson et al. 1982) were also plotted. Diversity was calculated as the ShannonWiener diversity index $H^{\prime}$, using logarithms to the base $\mathrm{e}$ in the calculations, species richness as Margalef's $D$ and evenness as Pielou's J. Hill's (1973) diversity numbers were also calculated, as in Heip et al. (1988).

Species abundance and biomass patterns. The number of species in $\times 2$ geometric abundance classes $(1,2-3,4-7,8-15$ etc.) was plotted following Gray \& Pearson (1982). This method has been suggested as indicating effects of pollution stress and also as a method allowing the objective selection of groups of indicator species.

ABC (Abundance-Biomass Comparison) curves (Warwick 1986, Warwick et al. 1987), which use the $k$ dominance curves of Lambshead et al. (1983), were plotted for abundance and biomass data for the Frierfjord samples. This technique was not used on the mesocosm data since the core samples taken did not adequately sample the larger, high biomass organisms. Warwick has suggested that the relation between species abundance and species biomass curves can indicate pollution-induced stress. Where the biomass curve lies above the abundance curve the assemblage is not affected by pollution, where the 2 curves cross one another the first stages of pollution-induced change occur, and where the abundance curve lies above the biomass curve the assemblage is from a grossly polluted habitat.

\section{RESULTS}

Four distinct stages in the identification of pollution effects can be recognized.

(1) Multivariate methods used to discriminate between sites based on their faunal attributes: classification, ordination and discrimination tests.

(2) Univariate methods used to determine levels of disturbance or 'stress' at given sites.

(3) Correlation of (1) and (2) above with measured pollution levels.

(4) Experimental investigation of cause and effect relations.

The results presented below are considered under these headings.

\section{Discrimination between sites}

Fig. 1 shows the classification analysis for species abundance $(A)$ and biomass ( $B$ ) based on data in Tables 1 and 2 of Appendix 3. On both dendrograms, Sites $A$, $E$ and $G$ are clearly separated from each other and from a group of sites comprising B, C and D. However, within this latter group, Site $D$ is distinct whereas $B$ and $C$ are inseparable. Figs. 2 a to $d$ show MDS analyses for both abundance and biomass with the 4 th root and untransformed data. In all cases 'stress coefficients' are low, of the order of 0.1 or less, and 2-D plots are adequate. For the 4 th root transform (Fig. 2a, b) there are 3 major clusters: Sites $B+C+D$, Sites $E+G$ and Site A occupying an intermediate but somewhat offset position. In the abundance plot (Fig. 2a) Sites E and G, although close together, are clearly separate, but on the biomass plot (Fig. 2b) they are indistinguishable. $B$, $C$ and $D$ do not appear distinct on either the abundance or biomass plots, but these 3 sites have been analysed separately (Fig. 2e,f), and the ANOSIM test does indicate a significant separation between them; the pairwise comparison shows that Site D differs from both 


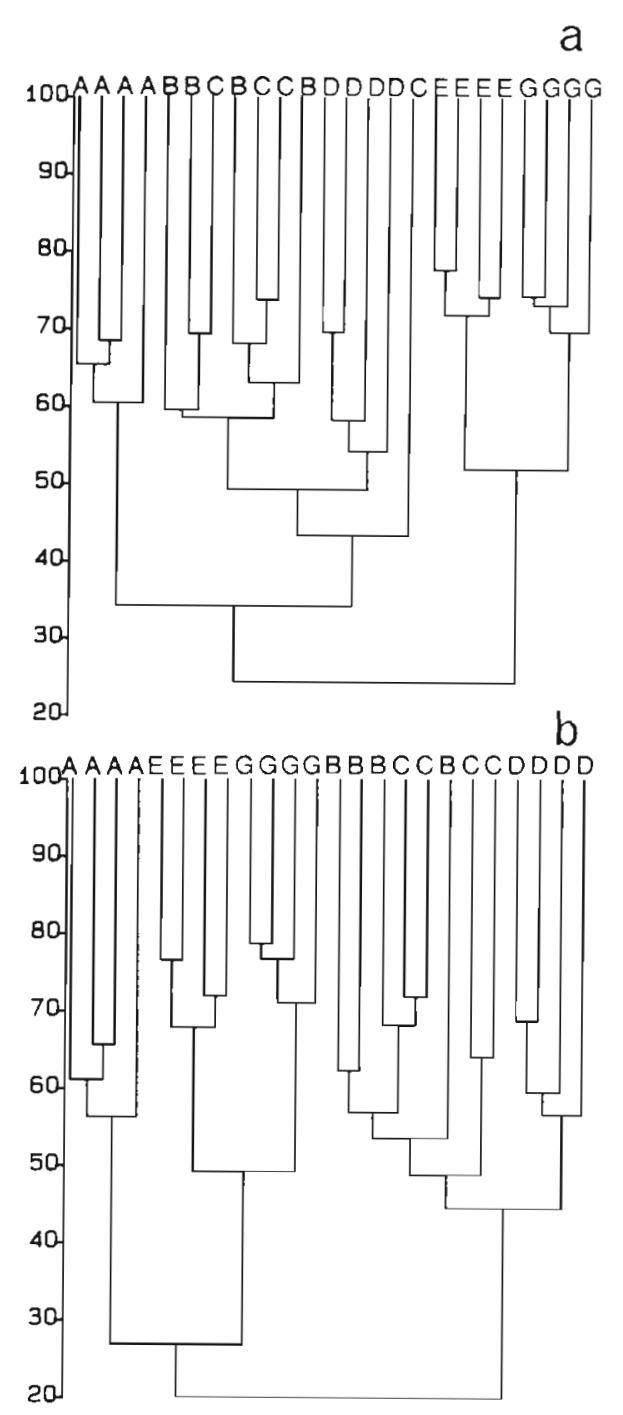

Fig. 1. Dendrogram for group-average clustering of BrayCurtis similarities ( $y$-axis) between the 24 field macrofaunal samples ( $x$-axis), consisting of 4 replicate grabs at each of Sites A to $E$ and $G$. (a) Species abundance data, Appendix 3, Table 1. „-transformed; (b) Species biomass data, Appendix 3, Table 2, „-transformed

$\mathrm{B}$ and $\mathrm{C}$ but that these last two are not significantly different.

For untransformed data, the MDS configurations (Fig. 2C, d) show a clearer separation of Sites $E$ and $G$, Site G (closest to the pollution source) occupying a position intermediate between Site $E$ (the next closest) and $A$ (furthest from the source). Site $G$ is closer to $A$ on the biomass plot (Fig. 2d) than on the abundance plot (Fig. 2C), and on the biomass plot Site $D$ becomes clearly separated from the $B+C$ cluster (although it is still close to it). Inspection of the raw data tables (Appendix 3, Tables 1 and 2) shows that values for

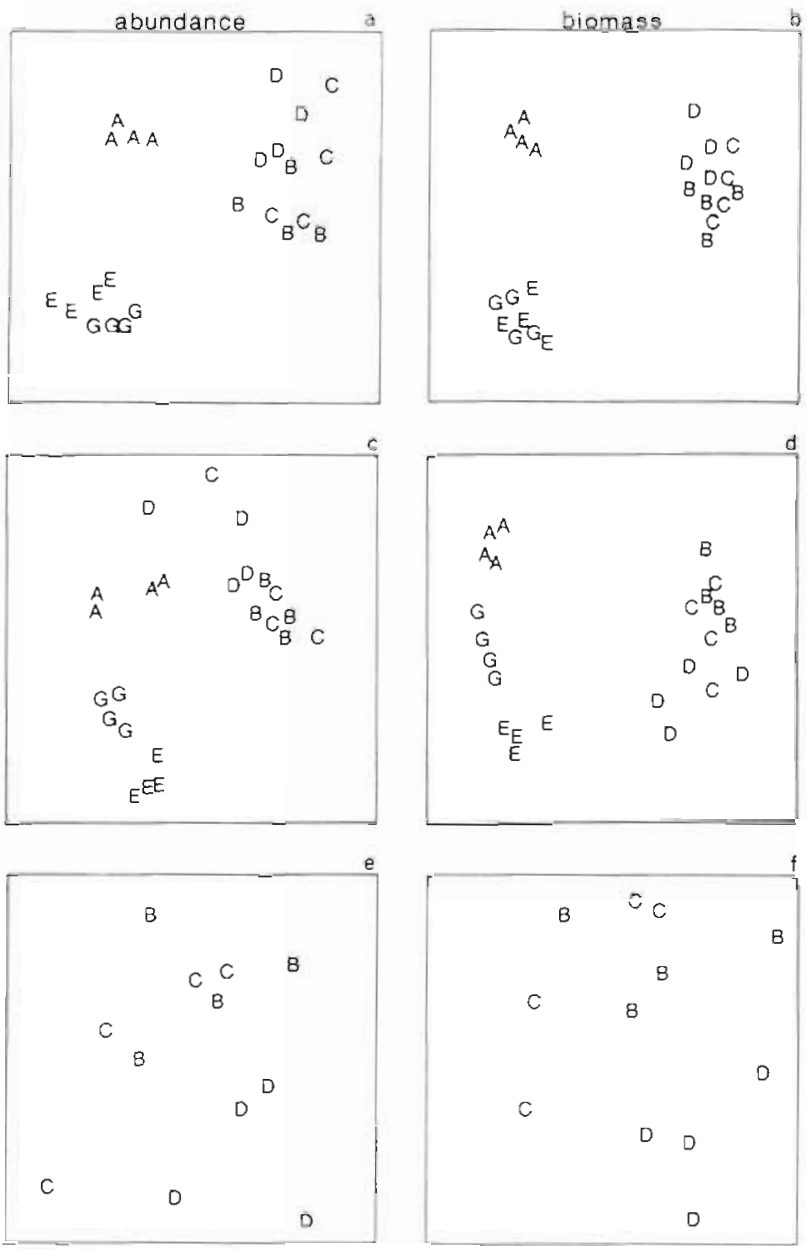

Fig. 2. Multi-dimensional scaling (MDS) ordination, based on Bray-Curtis similarities between grab samples of field macrofauna; samples are grouped by similarity in species counts (orientation and scale arbitrary). (a) , -abundance, Sites $A$ to $E$ and $G_{i}(b)$-biomass, Sites $A$ to $E$ and $G ;(c)$ raw abundance, Sites $A$ to $E$ and $G_{i}$ (d) raw biomass, Sites $A$ to $E$ and $G ;(e)$... abundance, Sites B to D; (f) ,-biomass, Sites B to D. Stress coefficients are (a) 0.10, (b) 0.09 , (c) 0.07 , (d) 0.11 , (e) 0.12 , (f) 0.10

species biomass are much more disparate than those for abundance, so that the effect of transformation in reducing the importance of biomass dominants is greater than its effect on numerical dominants (Clarke \& Green 1988). Thus, for example, Sites A and G are closer to each other in their biomass dominants (principally the echinoid Echinocardium cordatum), but less so in their numerical dominants; hence their proximity on the untransformed biomass plot (Fig. 2d).

Results of DECORANA analyses are shown in Fig. 3. Sites $A, E$ and $G$ are clearly separated and $B, C$ and $D$ group together. Within this latter group $D$ is relatively distinct, whereas $B$ and $C$ are inseparable. In the RA analysis on untransformed (Fig. 4) and transformed abundances, B, C and D form a common inseparable 
Fig. 5. Plots of number of species against individuals per species in geometric classes, at Sites A to E and G. (Class intervals: $\mathrm{I}=1$ individual per species, II $=2$ to 3 ind., III $=4$ to 7 ind., IV $=8$ to 15 ind., etc.)
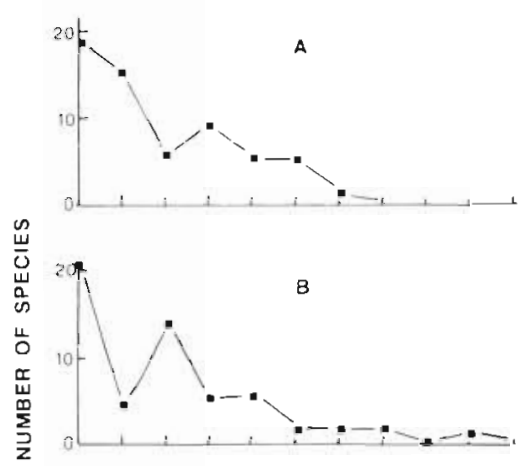

8
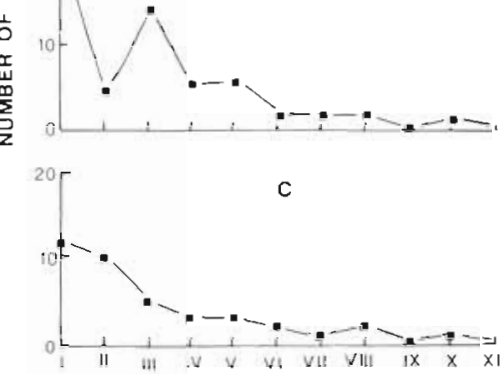

D

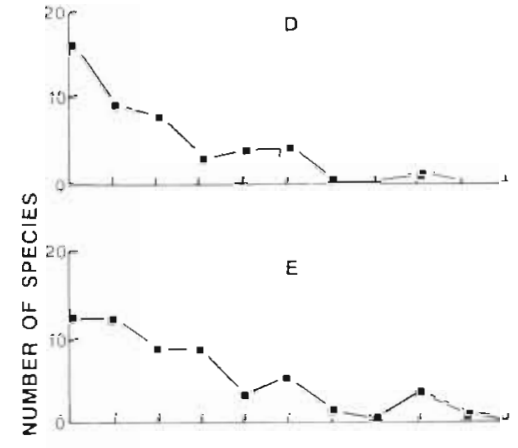

G

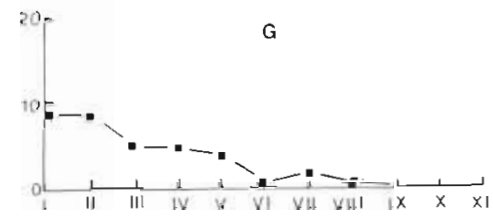

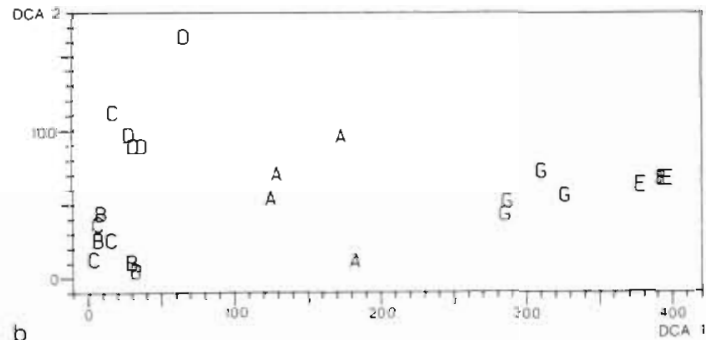

NUMBER OF INDIVIDUALS PER SPECIES ( $\times 2$ GEOMETRIC CLASSES

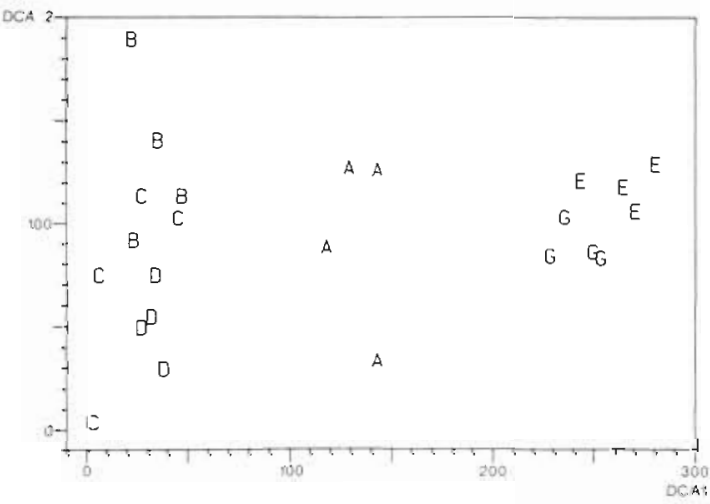

Fig. 3. Detrended Correspondence Analysis (DECORANA) ordination of field macrofaunal abundance data. (a) No transformation, (b) ",-transformation

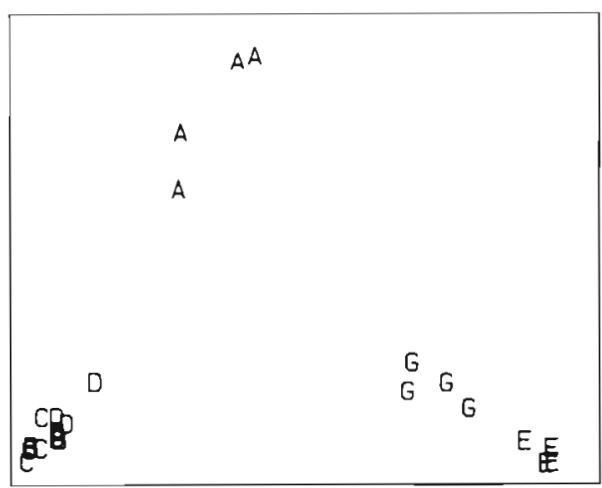

Fig. 4. Reciprocal Averaging (RA) ordination of field macrofaunal abundance data; no transformation

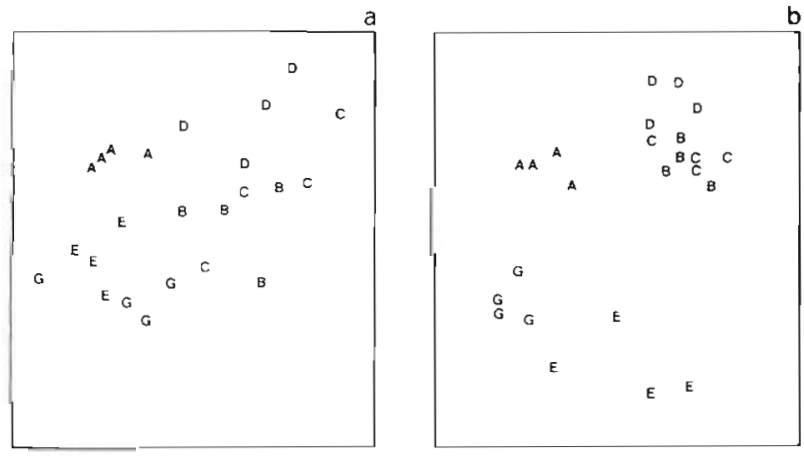

Fig. 6. MDS ordination of field macrofaunal samples from Sites $A$ to $E$ and $G$, based on , -transformed abundances of a subset of the full species matrix. (a) Selection of 19 species of midrange abundance (Geometric classes III to V), following Gray \& Pearson (1983); stress $=0.14$; (b) selection of 19 species at random, from the full set of 110 species; stress $=0.13$

cluster. A, E and $G$ form separate clusters, with $G$ close to $E$ (no transformation), very close to $E$ but still separable from it (square root), or forming a common cluster with $E$ (4 th root). A is always clearly separated from the $B+C+D$ cluster and from $E$ and $G$.

Summarizing, the multivariate methods clearly separate Site $A$ from $E$ and $G$ and these from the remaining sites, B, C and D. Some techniques separate Site D from $B$ and $C$, but these three sites have close affinities.

The above analyses used the full species matrix. It has been suggested by Gray \& Pearson (1982) that a smaller group of species can be objectively selected which are the most sensitive to pollution-induced changes in benthic communities and might best illustrate the differences between them. To test this idea the species occurring in Geometric classes III to $\mathrm{V}$ (abundances of 8 to 63 individuals), from the pattern of the distribution of individuals among species (Fig. 5), were identified following Pearson et al. (1983). An MDS 
analysis was done on the 19 species selected and Fig. $6 \mathrm{a}$ shows the results. Although site groupings are similar to those obtained with the full data set (Fig. 2a), differentiation between groups is less clear-cut, as is to be expected, since species present in higher geometric classes clearly influence the results. There is a degree of redundancy in the full species matrix since any randomly selected subset of 19 species will recover much of the structure in the MDS plot for the full data set. Fig. $6 \mathrm{~b}$ shows the result of one such random selection, which in fact separates the sites better than the objectively selected species subset. Other random subsets showed equally good separation. The conclusion here is that the site differences are so strong that any reasonably large group of species will show the same pattern.

\section{Determination of disturbance or stress}

The above multivariate methods give no indication of the underlying causes of species differences between sites. Univariate measures are used to ascertain whether these differences can be associated with adverse conditions which result in disturbance or

Table 1. Basic descriptive variables for macrofauna samples from Field sites A to $E, G$ : water depth $(m)$, number of taxa $S$, total biomass $B\left(\mathrm{~g} \mathrm{~m}^{-2}\right)$, number of individuals $A\left(\mathrm{~m}^{-2}\right)$, species diversity $H^{\prime}$, evenness $J$, richness $D$

\begin{tabular}{|c|c|c|c|c|c|c|c|}
\hline Site & $\begin{array}{l}\text { Water } \\
\text { depth }\end{array}$ & $S$ & $B$ & $A$ & $H^{\prime}$ & $J$ & $D$ \\
\hline \multirow[t]{4}{*}{ A } & 76 & 32 & 189.9 & 1430 & 2.92 & 0.84 & 6.25 \\
\hline & & 28 & 341.5 & 1080 & 2.64 & 0.79 & 5.77 \\
\hline & & 37 & 283.2 & 1350 & 3.16 & 0.87 & 7.34 \\
\hline & & 39 & 267.5 & 1500 & 3.26 & 0.89 & 7.58 \\
\hline \multirow[t]{4}{*}{$B$} & 113 & 42 & 103.2 & 6570 & 2.28 & 0.62 & 6.32 \\
\hline & & 21 & 24.3 & 2750 & 1.66 & 0.55 & 3.56 \\
\hline & & 35 & 45.8 & 4040 & 2.13 & 0.60 & 5.66 \\
\hline & & 27 & 30.4 & 4720 & 1.61 & 0.49 & 4.22 \\
\hline \multirow[t]{4}{*}{ C } & 108 & 14 & 8.7 & 430 & 2.05 & 0.78 & 3.45 \\
\hline & & 20 & 17.2 & 3230 & 1.48 & 0.49 & 3.29 \\
\hline & & 26 & 40.0 & 4210 & 1.64 & 0.50 & 4.14 \\
\hline & & 26 & 63.5 & 8660 & 1.59 & 0.49 & 3.70 \\
\hline \multirow[t]{4}{*}{$\mathrm{D}$} & 101 & 21 & 15.1 & 950 & 1.87 & 0.61 & 4.39 \\
\hline & & 32 & 23.5 & 2700 & 2.22 & 0.64 & 5.54 \\
\hline & & 17 & 11.7 & 760 & 2.39 & 0.84 & 3.69 \\
\hline & & 24 & 19.4 & 2360 & 1.94 & 0.61 & 4.21 \\
\hline \multirow[t]{4}{*}{$E$} & 22 & 35 & 60.1 & 4410 & 3.47 & 0.68 & 5.58 \\
\hline & & 34 & 83.5 & 5840 & 3.30 & 0.65 & 5.18 \\
\hline & & 37 & 83.3 & 5680 & 3.25 & 0.62 & 5.68 \\
\hline & & 28 & 78.5 & 4740 & 3.19 & 0.66 & 4.38 \\
\hline \multirow[t]{4}{*}{$\mathrm{G}$} & 23 & 22 & 110.8 & 1920 & 2.31 & 0.75 & 3.99 \\
\hline & & 21 & 69.4 & 2060 & 2.11 & 0.69 & 3.75 \\
\hline & & 22 & 155.6 & 1470 & 2.18 & 0.70 & 4.21 \\
\hline & & 20 & 74.3 & 1150 & 2.28 & 0.76 & 4.00 \\
\hline
\end{tabular}
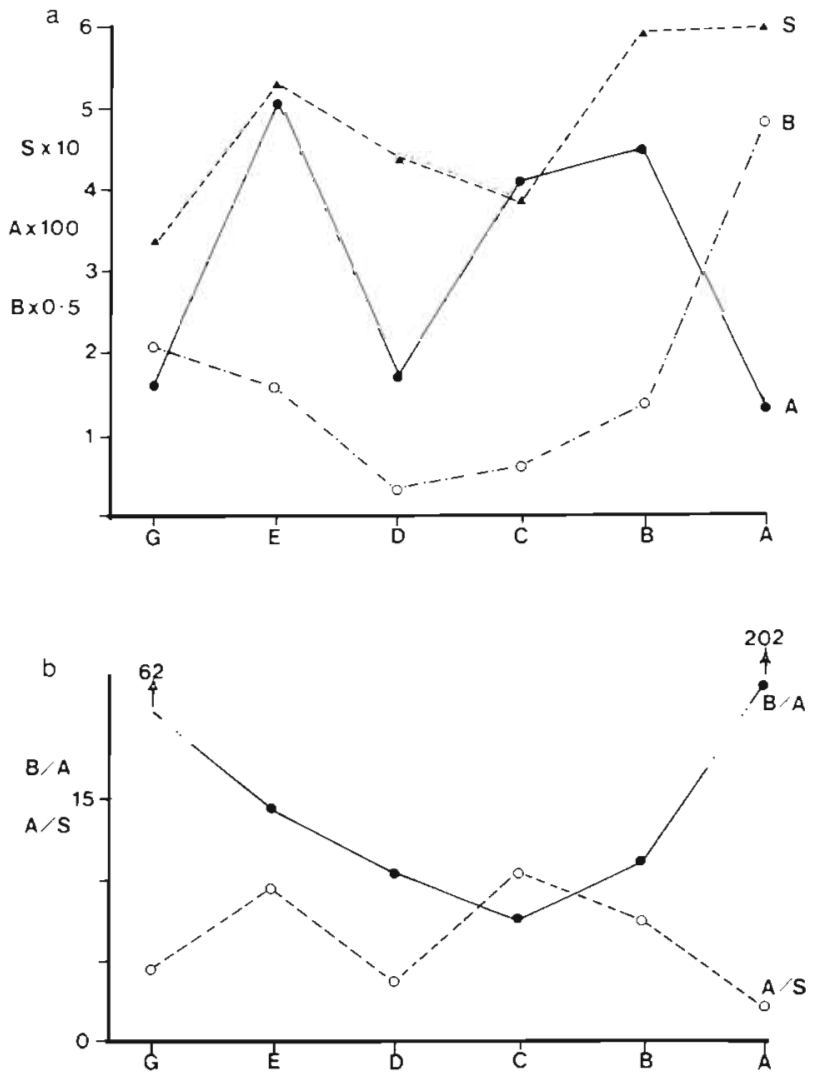

Fig. 7. (a) SAB curves ( $S$ : total number of species, $A$ : mean abundance per $0.1 \mathrm{~m}^{2}, B$ : mean biomass in $\mathrm{mg}$ per $0.1 \mathrm{~m}^{2}$ ), plotted across Sites A to $E$ and $G$. (b) $B / A$ and $A / S$ plots across sites

stress. These measures fall into 2 categories: those which require reference to 'control' sites either spatially or over time, and those in which the level of stress can be determined without such comparative data.

\section{Comparisons between sites along a gradient}

Table 1 shows that the outermost site A has the highest number of taxa and the highest mean biomass, but the lowest mean abundance. The mean biomass was particularly low at Sites C and D. Fig. 7 shows the data in Table 1 plotted as SAB curves and as ratios of biomass to abundance $(B / A)$ and abundance to species number $(A / S)$. The ratio $B / A$ was highest and $A / S$ lowest at Sites $A$ and $G$ suggesting that these sites are relatively undisturbed. The remaining sites $(B, C, D$ and $E$ ) have similar values and suggest that they have a different structure to $\mathrm{A}$ and $\mathrm{G}$. Site $\mathrm{E}$ is however much shallower than the other sites $(22 \mathrm{~m})$, compared with $B$ $(113 \mathrm{~m}), \mathrm{C}(108 \mathrm{~m})$ and $\mathrm{D}(101 \mathrm{~m})$. Fig. 8 shows the means and ranges of diversity and evenness. Site $E$ had highest mean Shannon diversity, closely followed by A, 


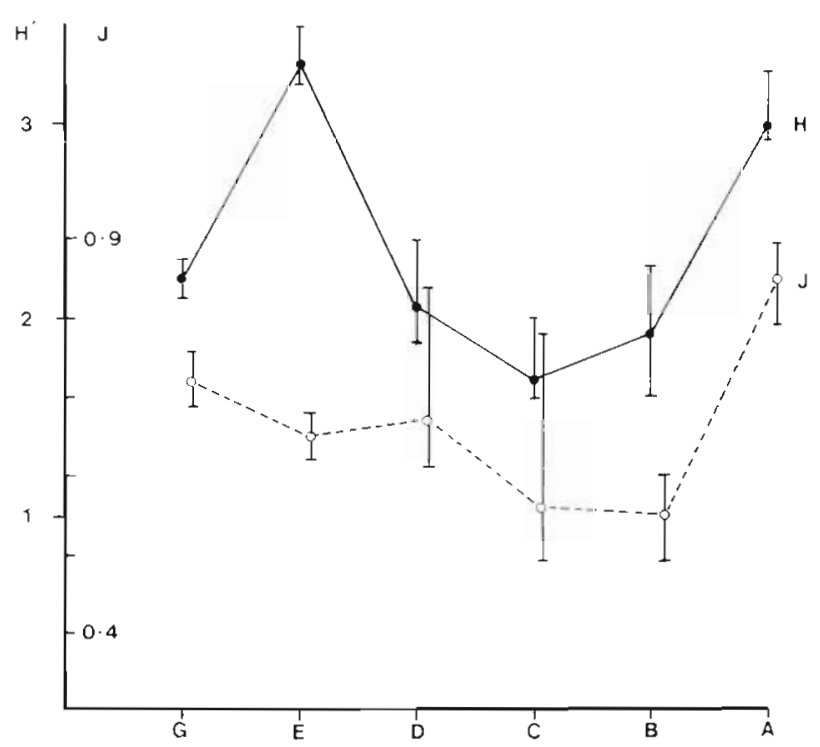

Fig. 8. Diversity $\left(H^{\prime}\right)$ and evenness $(J)$ across sites. Vertical bars: maximum and minimum values

but Margalef's species richness (D) showed highest values at $A$. Evenness was however highest at Site $A$ whereas Sites B and $C$ had lowest values. These data suggest that Site $\mathrm{A}$ is less disturbed than the remaining sites.

In order to examine whether there are clear differences between sites in the combination of univariate measures given in Table 1, we have subjected them to a Principal Components Analysis (PCA, Fig. 9). This analysis can be envisaged as a PCA site ordination, but with the set of diversity measures substituted for species abundances in the sites-species matrix. The first $P C$ axis (PC1) is a roughly equally weighted average of the normalised values of total biomass, $S, H^{\prime}, J$

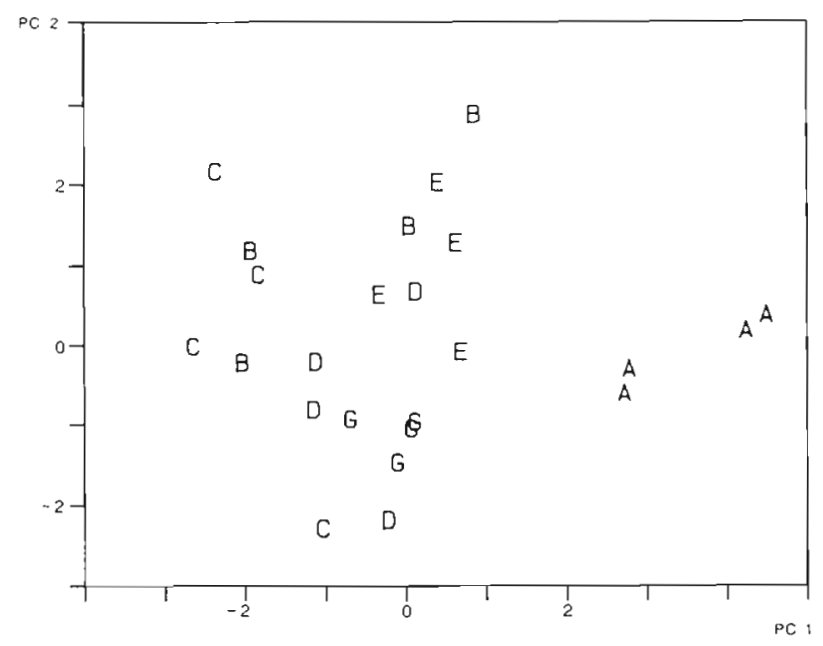

Fig. 9. Principal Components Analysis (PCA) of the 6 univariate community measures listed in Table 1, for the 24 field samples. Measures were normalised (but not transformed) prior to PCA. The first 2 PCs account for $89 \%$ of the variability and $D$, contrasted with the total number of individuals; it accounts for $60 \%$ of the variability. It clearly separates Site $\wedge$ as a high diversity, high biomass site. PC2 contrasts $J$ with a combination of $S, D$ and the total number of individuals; it accounts for all but $11 \%$ of the remaining variability in the full matrix. The PCA fails to discriminate clearly between all sites except $A$, the replication variance being particularly high for Sites $B, C$ and $D$. (In fact, this greater variability may in itself be indicative of disturbance.)

Addition of Hill's diversity numbers to this ordination did not improve separation of sites. In fact the resulting PCA is largely unchanged, with the first 2 PC's again accounting for most of the variability, a consequence of the high correlation between the various diversity measures. It is instructive to compare Fig. 9 with the multivariate analyses of the species abundance/biomass matrices (Fig. 2). The latter depend on matching observations on each individual species and, as might be expected, are able to discriminate the sites more clearly.

Fig. 10 shows the dominance pattern of the highest ranked species in abundance and biomass. The polychaete Heteromastus filiformis dominates numeri-

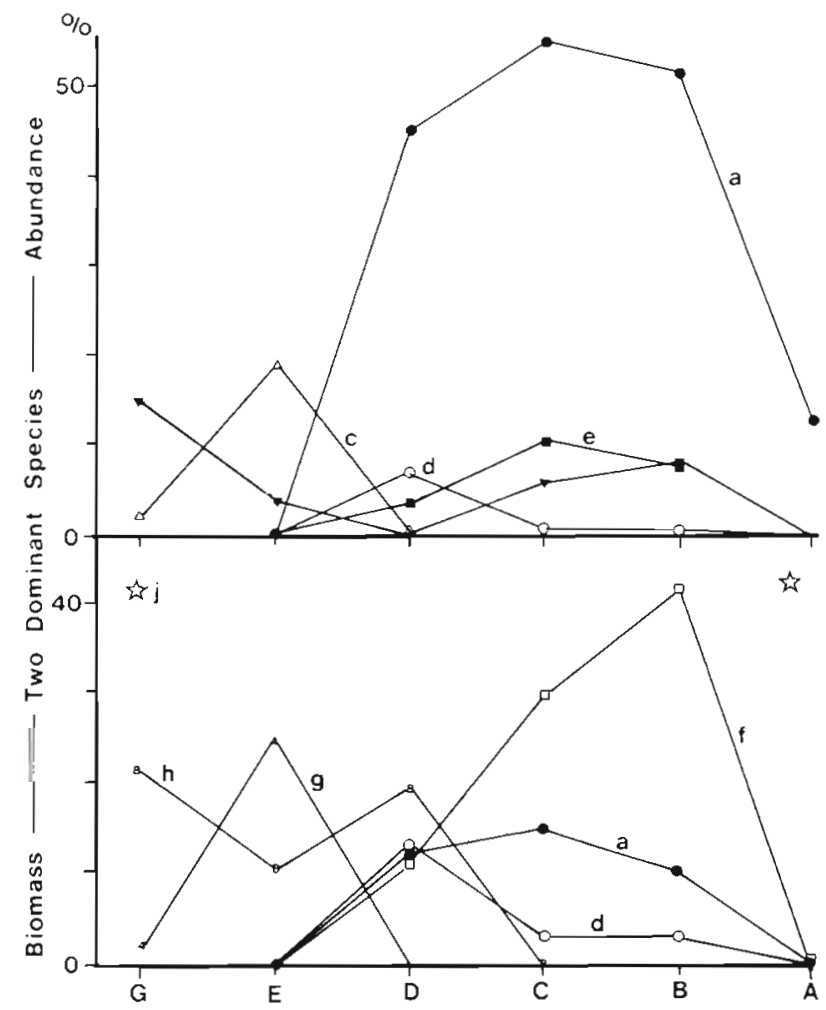

Fig. 10. Abundance and biomass patterns of the 2 dominant species at each sampling site. a: Heteromastus filiformis, b: Myriochele oculata, c: Labidoplax buski, d: Nucula nitida, e: Cossura longocirrata, f: Nepthys ciliata, g: Myrtea spinifera, h: Thyasira flexuosa, j: Echinocardium cordatum 
cally at Sites A, B, C and D and constitutes over $45 \%$ of the total at Sites $B, C$ and $D$, suggesting that these 3 sites are organically enriched, as high numbers of this species are associated with such enrichment (Rosenberg 1976). In terms of biomass dominance the polychaete Nephtys ciliata dominates at B and C, whereas the echinoderm Echinocardium cordatum dominates at $A$ and $G$, suggesting the latter sites are not polluted (Rosenberg 1972).

Dividing the species into feeding groups (Fig. 11)

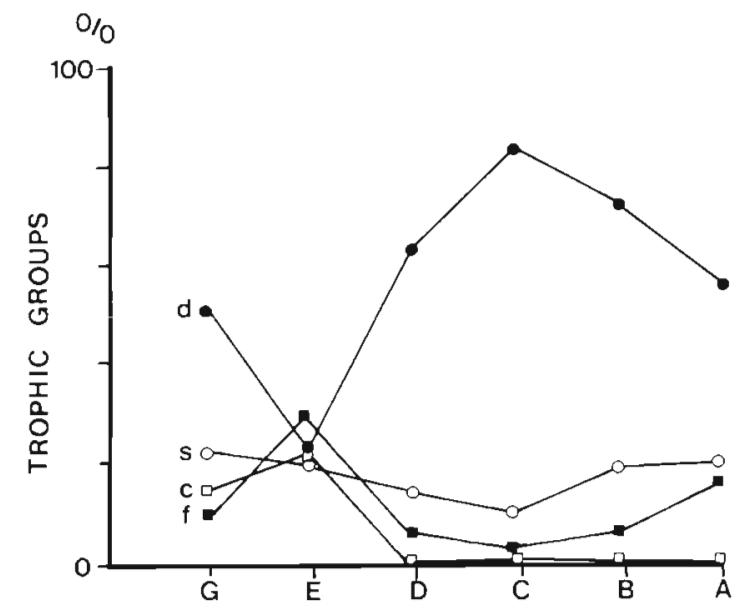

Fig. 11. Feeding groups across sites. (•) Sub-surface deposit feeders (d); (o) surface deposit-feeders (s); (a) suspension. feeders (f); open $(\square$ ) carnivores (c)

shows that the shallow E site has an equal proportion of surface deposit feeders, sub-surface deposit feeders and carnivores, whereas the deeper sites $(A, B, C, D$ and $G$ ) are dominated $(>55 \%)$ by sub-surface deposit feeders. It is known that organic enrichment favours deposit feeders (Pearson \& Rosenberg 1978). Sites A and $G$, which from the analyses discussed above differ from the other sites, cannot be separated from them here.

Plots of the distribution of individuals among species (Fig. 5) show that Sites $A$ and $G$ are the least stressed, whereas more geometric classes are covered by the plots for the other sites, which in general have flatter curves suggesting that they represent more disturbed communities. By comparison with other data (e.g. in Pearson et al. 1983), B and E appear to be more disturbed than $C$ and $D$.

Determination of disturbance at individual sites

Fig. 12a shows the relative composition of the dominant faunal groups (polychaetes, molluscs, echinoderms and
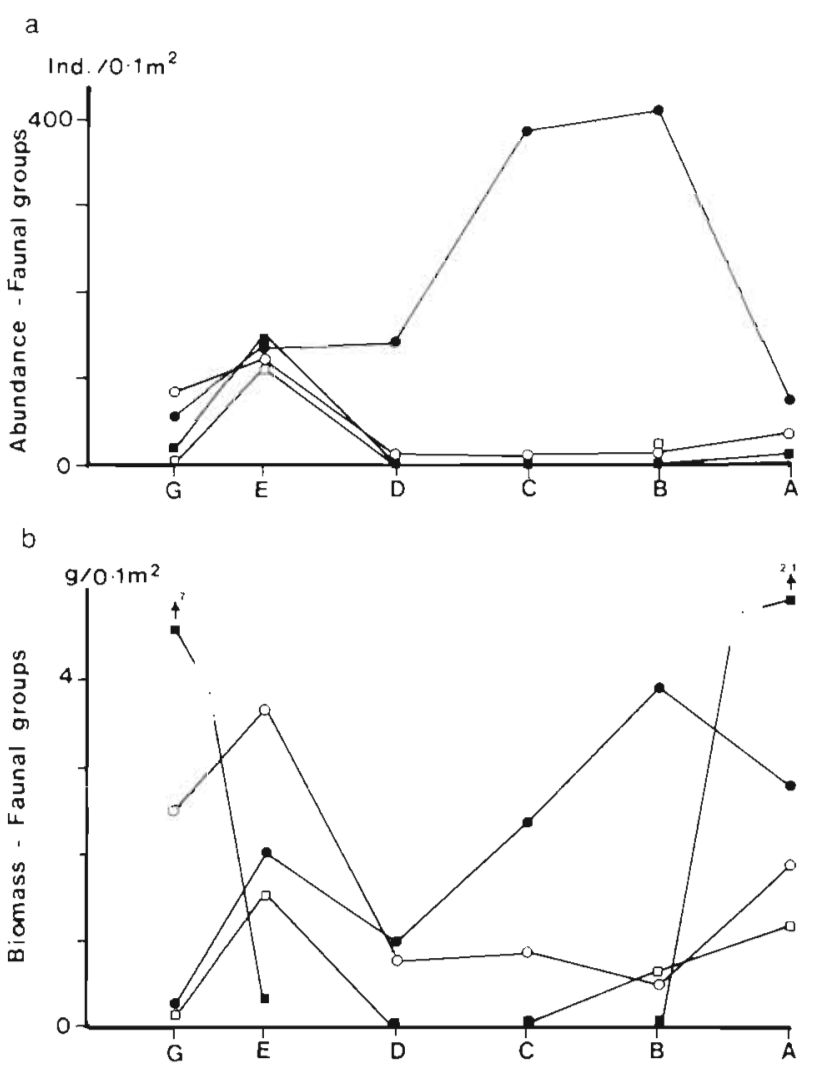

Fig. 12. (a) Abundance and (b) biomass plots of faunal groups. (-) Polychaetes; (O) molluscs; ( $)$ echinoderms; ( $\square$ ) other groups

'others'). Whereas Site E has an approximately equal proportion in terms of abundance of each group, polychaetes dominate at the other sites and particularly at Sites B, C and D. Rosenberg (1972) has suggested that numerical dominance of polychaetes and a paucity of echinoderms could indicate organic enrichment. Fig. $12 \mathrm{~b}$ shows biomass proportions of the same groups. Molluscs dominate at $E$, echinoderms at $A$ and $G$ and polychaetes at the other sites. Following Rosenberg (1972) this suggests that A and G are unpolluted.

Fig. 13 shows ABC plots for both abundances and biomass. At the outermost $(A)$ and innermost $(G)$ sites the biomass curve lies above the abundance curve indicating unpolluted habitats. The $A B C$ plots for the middle 2 sites (C and D) indicate a condition intermediate between Warwick's (1986) 'moderately polluted' and 'grossly polluted' conditions, with the biomass curve well below the numbers curve for the most dominant species but then crossing it. The intermediate sites (B and E) indicate 'moderately polluted' conditions, with the biomass and abundance curves quite closely coincident. This method, as with the other methods described in this section, shows a gradient of disturbance which is most intense at the middle sites. 


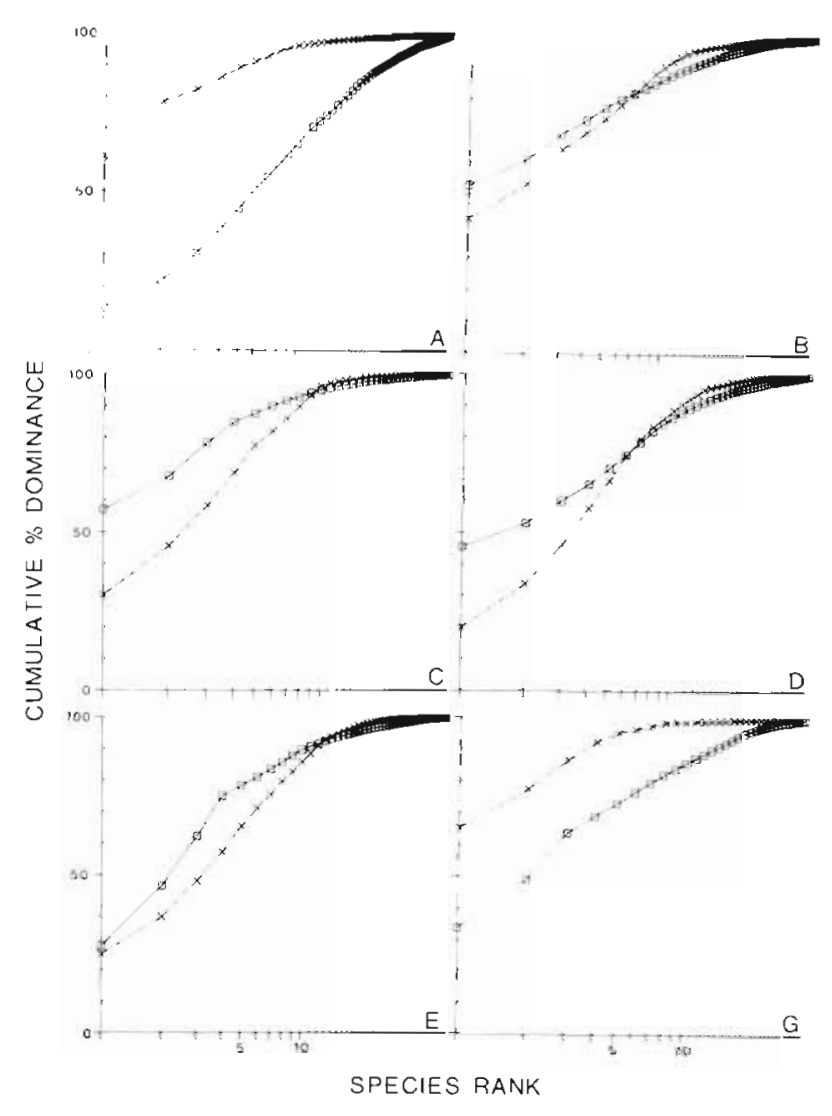

Fig. 13. ABC plots for field macrofauna across sites. $k$-dominance curves for abundance (squares and solid lines) and biomass (crosses and broken lines) are based on the totals from the 4 replicates at each site

\section{Correlation with anthropogenic inputs}

Clearly, any attempt to interpret changing biological patterns in terms of contaminant loadings should be prefaced by a demonstration that these loadings do differ significantly between sites. Available sediment chemistry data for the field study consisted of 2 replicate cores from each of the Sites A to $G$ analysed for a suite of PAHs (Appendix 1, Table 2), and 3 replicate cores from each site analysed for a suite of metals (Appendix 1, Table 12).

Demonstration of between-site differences again involved a multivariate analysis, chemical 'species' replacing the faunal species of the previous biological analyses. Treating the metal and PAH matrices separately, the entries were subjected to a square root transformation to reduce the apparent right-skewness of the error distribution, and input to a correlationbased PCA. The resulting ordinations of the replicate cores within Sites A to $G$ are shown in Fig. 14a for metals and Fig. 14b for PAHs. In both cases the first principal component axis ( $\mathrm{PC} 1$ ) is interpretable as a
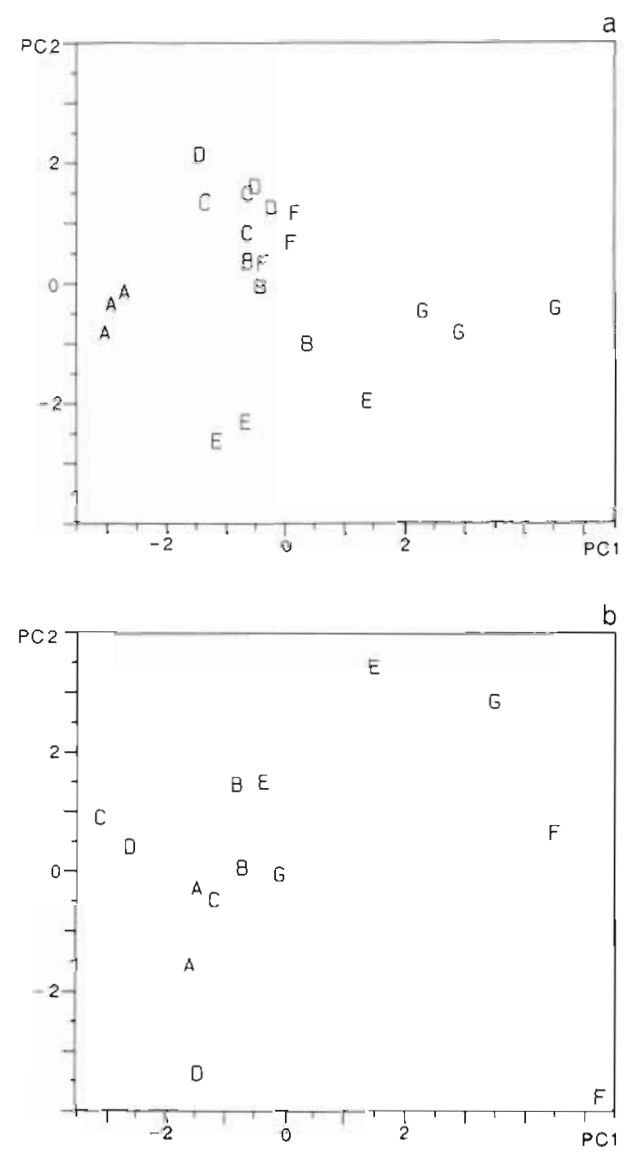

Fig. 14. PCA ordination of sediment chemistry data from Field sites $A$ to $G$; concentrations in the top $2 \mathrm{~cm}$ were -transformed and normalised prior to PCA. (a) Metal concentrations (Appendix 1, Table 12); the first PC axis represents increasing contaminant load, the weights given to the normalised $(\mathrm{Cu}$, $\mathrm{Zn}, \mathrm{Pb}, \mathrm{Ni}, \mathrm{Cr}, \mathrm{Cd}, \mathrm{Mn}, \mathrm{Fe})$ levels being $(0.41,0.48,0.46,0.30$, $0.35,0.35,-0.05,-0.21)$ respectively. (b) Concentrations of selected PAHs (Appendix 1, Table 2), the first PC axis again representing increasing contaminant load, with positive and comparable contributions from all the (normalised) PAHs. The first 2 PCs account for 69 and $59 \%$ of the variability in (a) and (b) respectively

sum over the levels of all chemicals and so represents an axis of increasing contaminant load, from left to right. Using a variation of the ANOSIM test appropriate to a PCA (Clarke \& Green 1988), the hypothesis that there are no between-site differences can be rejected, for metals at $p<0.001$ and for PAHs at $p<0.05$, thus demonstrating a clear difference between sites. The outermost site (A) shows the lowest heavy metal loading with $B, C, D$ and $E$ intermediate and $G$ the highest loading. There is a suggestion that, for the deeper sites, the analysis of the metal data separates $B$ from $C$ and $D$, as was the case more markedly with sediment physical attributes (see Fig. $14 \mathrm{a}$, also Table 5 of Follum \& Moe 1988); by contrast the biological data tend to separate $\mathrm{D}$ from $\mathrm{B}$ and $\mathrm{C}$. The gradient for PAHs is more con- 
fused and it is uncertain whether this reflects greater field variation or greater analytical variability.

By superimposing measured environmental factors on the 2-D configurations of site positions from the faunistic multivariate analyses, indications can be obtained of the variables that correlate with group differences (Field et al. 1982). Fig. 15 shows the MDS configuration from 4 th root transformed species abundances (Fig. 2a), with superimposition of 2 natural variables, water depth (Fig. 15a) and median grain size (Fig. 15b), and 2 pollution variables, metal level (Fig. 15c) and 'total' PAH (Fig. 15d). Neither sediment type,

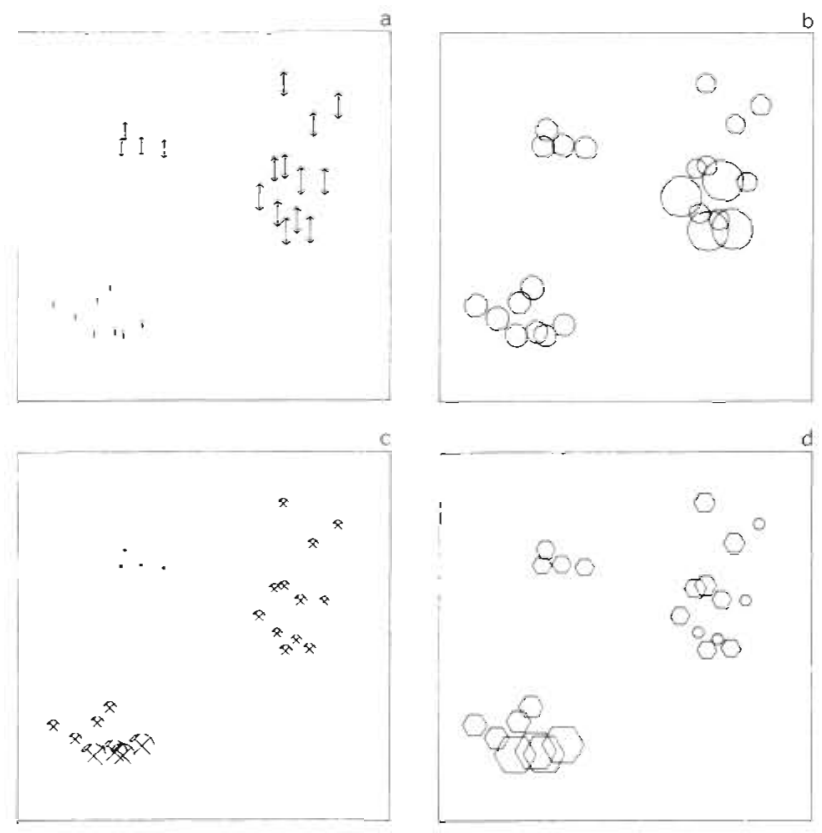

Fig. 15. MDS ordination of the 24 field macrofaunal samples from Sites $A$ to $E$ and $G$, exactly as in Fig. $2 a$, with superimposed symbols of lineal dimensions proportional to the values of selected environmental variables at these sites. (a) Water depth (smallest symbol represents $22 \mathrm{~m}$, largest $113 \mathrm{~m}$ ); (b) median particle diameter of sediment (smallest $7.8 \mu \mathrm{m}$, largest $16.5 \mathrm{um}$ ); (C) metal concentration in sediment: mean PC1 score from Fig. $14 \mathrm{a}$, representing an average of $\mathrm{Cu}, \mathrm{Zn}, \mathrm{Pb}, \mathrm{Ni}, \mathrm{Cr}$, $\mathrm{Cd}$ levels (smallest -2.9 , largest +3.2 ) i (d) 'total' PAH concentrations in sediment (smallest $4.4 \mu \mathrm{g} \mathrm{g}^{-1}$, largest $14.8 \mathrm{\mu g} \mathrm{g}^{-1}$ )

metals or PAH correlate closely with the site positions. The $B+C+D$ site cluster has sediments with both the largest and smallest median particle diameters. For metals, the $E+G$ cluster has both very high and intermediate metal levels, and the situation for PAH levels is similar. Using Occam's Razor the simplest explanation for the trends in the data is that depth has an overriding influence on the macrofaunal distribution patterns, since depth increases in a uniform manner from left to right in the MDS plot (Fig. 15a). Since the DECORANA and RA configurations (Figs. 3 and 4) were closely similar to the MDS plot (Fig 2), similar observations would have followed from superimposing the same environmental factors on either of these configurations.

The interpretation of the objectively derived groupings and the possible effects of environmental and pollution-related gradients can be further examined using the biological data and knowledge of how species and groups respond to various disturbing factors. Table 2 represents a summary of the biological criteria used to interpret the differences between sites. It shows that Site $\mathrm{A}$ is unaffected by disturbance. Rygg et al. (1985) also regarded this site as unpolluted. At A the benthic community has a high diversity, a high biomass, a high $B / A$ ratio and a low $A / S$ ratio. Pollution data (Fig. 14) show that Site $A$ has the lowest loading. The highest loading is at Site $G$, which is similar to $A$ in most biological analyses. However, this site has generic dominants which are typical for organic enrichment: Thyasira, Corbula, Labidoplax, Myriochele, Mediomastus, Myrtea, Prionospio and Scololplos (Pearson et al. 1983) which do not occur at A. If this is an effect induced by chemical pollutants, it closely parallels the effects of mild organic enrichment; a similar effect was noted by Warwick et al. (1988) in the mesocosm experiment for meiofauna.

Whilst the ABC plots (Fig. 13) and the individuals among species pattern (Fig. 5) suggest that Site $E$ is disturbed, other factors such as the high number of species, the similarity in proportions of the faunal groups and the low variance in abundance and diversity between samples (Table 1) suggest that it is not disturbed. At $E$ therefore, the data are equivocal.

Sites B, C and D have similar water depths. A number of biological variables (shown in Table 2) suggest that these sites are subject to environmental disturbance. Based on the summed indications of disturb-

Table 2. Appraisal of indication of disturbance effects on benthic macrofaunal communities from Frierfjord/Langesundfjord

\begin{tabular}{|lcccccc|}
\hline Community attributes & A & B & C & D & E & G \\
\hline Total species numbers & - & - & - & - & - & 0 \\
Total abundance & - & - & - & - & - & - \\
Total biomass & - & 0 & $\bullet$ & $\bullet$ & - & - \\
Biomass/abundance & - & 0 & $\bullet$ & 0 & - & - \\
Abundance/species nos. & - & 0 & $\bullet$ & - & 0 & - \\
Faunal group abundance & - & $\bullet$ & $\bullet$ & - & - & - \\
Faunal group biomass & - & $\bullet$ & 0 & - & - & - \\
Abundance of dominants & - & $\bullet$ & $\bullet$ & $\bullet$ & - & - \\
Biomass of dominants & - & $\bullet$ & 0 & - & - & - \\
Diversity and evenness & - & 0 & 0 & - & - & 0 \\
$k$-dominance curves & - & 0 & $\bullet$ & $\bullet$ & 0 & - \\
Trophic group abundance & - & 0 & 0 & - & - & - \\
Ind among species dist. & - & $\bullet$ & $\bullet$ & 0 & $\bullet$ & - \\
- clear indication, 0 possible indication & & & & \\
\hline
\end{tabular}


ance a ranking from most to least disturbed is $\mathrm{C}>\mathrm{B}>$ $D$. The community at $C$ has the lowest number of species, the lowest diversity. the lowest $B / A$ ratio and the highest $A / S$ ratio of all the sites investigated. Its ABC plot was closest to the 'grossly polluted' condition. Rygg \& Skei (1984) found that this site had the lowest 'rarefaction' diversity of 5 sites sampled. Sites B, C and $D$ are located at water depths between 101 and $113 \mathrm{~m}$. At these depths there is unlikely to be any influence of wave activity nor of large short-term variations in temperature or salinity (Fig. 4 of Follum \& Moe 1988). The bottom water in these deeper parts of the fjord is, however, subject to annual fluctuations in oxygen content. In November 1984, the time of year when $\mathrm{O}_{2}$ concentrations are usually at their lowest in Norwegian fjords, Frierfjord $\mathrm{O}_{2}$ concentrations of 1.5 to $2.1 \mathrm{ml} \mathrm{O}$ $1^{-1}$ were recorded at 50 to $80 \mathrm{~m}$ depth. In the Langesundfjord, $2.5 \mathrm{ml} \mathrm{O}_{2} 1^{-1}$ was recorded at $105 \mathrm{~m}$ depth (Rygg et al. 1985). Thus low oxygen concentration, which usually reflects organic enrichment, is likely to be a major factor influencing the benthos at these sites. The low biomass and low $B / A$ ratios are typical features of organically enriched areas subjected to low oxygen concentrations (Pearson \& Rosenberg 1978, Pearson et al. 1982). The dominance by polychaetes in abundance and biomass and the lack of echinoderms are also typical for enriched areas (Rosenberg 1972). In a Swedish fjord subjected to organic enrichment, high abundances of the polychaete Heteromastus filiformis were recorded (Rosenberg 1976) as was the case at the 3 deep sites here

The most parsimonious explanation for the multivariate and univariate observations in respect of the major differences between communities is as follows.

(1) In the faunistically-based multivariate analyses, the well-known effect of water depth on benthic community type (e.g. Buchanan 1963) can explain the separation of the deep sites ( $B, C$ and $D$ ) from the shallower ones (A, E and G).

(2) The clear indications of disturbance derived from univariate techniques for the mid-transect sites ( $B, C$ and D) probably result from seasonal anoxia in the deeper basins of the fjord. Although these sites formed a united cluster in the multivariate analyses, it could not be established that this cluster corresponded to high values of any of the measured pollution variables, nor were these sites closest to the pollution source.

(3) Although clear differences were found between sites in multivariate analyses of the chemical data, the fauna at Site $G$, closest to the pollution source, showed at most slight indications of organic enrichment which could not be clearly related to chemical pollution.

This study demonstrates one of the main problems of environmental monitoring, that of separating pollution gradients from natural environmental gradients. The fjordic environment studied had a small tidal range $(20 \mathrm{~cm})$ and a chemical gradient resulting from some of the largost discharges of chemical waste to the marine environment in Norway. Yet a depth related influence on benthic community structure (probably low oxygen concentration) was clearly the overriding factor. Seasonal low oxygen concentrations are typical of many Norwegian fjords with poor water exchange and are not necessarily associated with increased organic enrichment. In the Frierfjord/Langesundfjord however, there is evidence (Rygg et al. 1985) that the low oxygen concentrations found, and consequent effects on the benthos, can be related to organic enrichment.

\section{Cause and effect relationships}

The macrofauna abundance and biomass arrays from the mesocosm experiment are presented in Appendix 3, Tables 3 and 4 , there being 2 replicate core samples from 4 boxes in each of the four basins $C, L, M$ and $H$. Clustering and ordination were carried out in a similar way to field data and Fig. 16 displays the 2-D MDS configuration resulting from Bray-Curtis similarities computed on 4 th root transformed species abundances. The 'stress coefficient' is relatively high at 0.17 , holding out the possibility of a clearer picture at higher dimensions. However, the cluster analysis also displays no obvious pattern and this conclusion is borne out formally by the ANOSIM test (which because it operates on the similarity matrix, rather than the derived MDS plot, is not restricted to a particular dimensionality). It fails to demonstrate any significant difference between basins, the statistic falling in the middle of the range of values expected under the hypothesis of 'no differences' ( $p=$ $0.47)$.

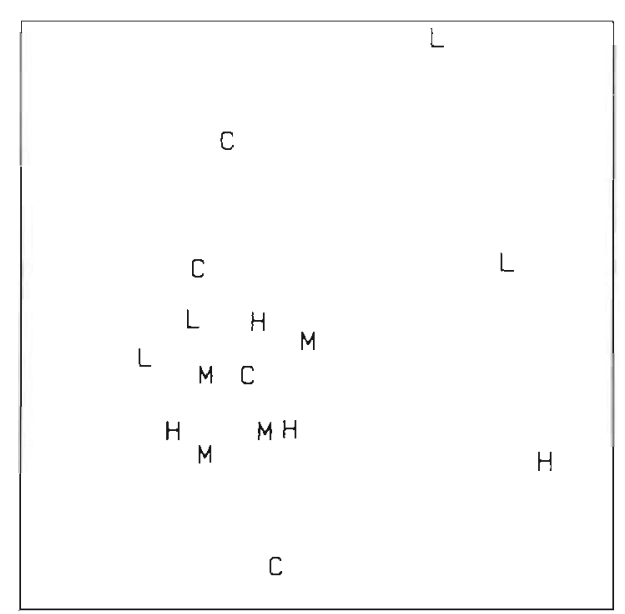

Fig. 16. MDS ordination of the 16 mesocosm macrofaunal samples, 4 replicates from each of Basins C, L, M and $H$. Ordination is based on Bray-Curtis similarities from ",-transformed species abundances. Stress coefficient $=0.17$ 
An ANOVA test for treatment level differences of PC1 and PC2 from a Principal Components Analysis (PCA) showed no significant differences between treatments, but on closer examination one can see that this is because differences among treatment levels are in PC3 and PC5, not in PC1 and PC2. The MANOVA, which is based on $\mathrm{PC} 1$ to PC5, shows a significant difference $(p=0.02)$ among treatment levels. The 5reatment level means are ordered C-L-M-H on the first canonical variate with the greatest separation being that of Level $\mathrm{H}$ from the others (Fig. 17). Note that, as discussed for the meiofaunal analysis in Warwick et al. (1988), this canonical variate plot should not be considered as an ordination comparable with PCA, MDS or DECORANA, since it exploits the known allocation of samples to treatment levels.

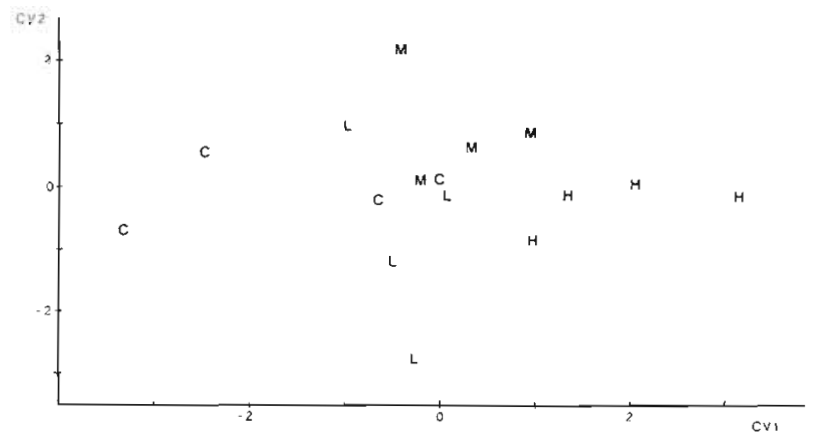

Fig. 17. Plot of Canonical variate 2 (CV2) versus Canonical variate 1 (CV1), for macrofaunal data from the 4 mesocosm treatments $\mathrm{C}, \mathrm{L}, \mathrm{M}$ and $\mathrm{H}$. Only CV1 should be interpreted because only $1 \mathrm{CV}$ axis is hypothesized, and only 1 axis is significant

The non-parametric and normality-based approaches reach rather different conclusions in this case. It is instructive, therefore, to compare like with like and carry out the ANOSIM test on the dissimilarity matrix implicit in a PCA analysis (under the same log transform, reduction in number of species and standardisation as used for the PCA). This non-parametric ANOSIM test again shows no significant differences between basins ( $p=0.82)$, in contrast to the parametric Roy's Greatest Root test for the same data ( $p=0.02)$. The latter test is clearly more sensitive, but relies on the validity of assumptions concerning multivariate normality and 'large' samples; the former test is a robust non-parametric technique with small-sample validity. The practical conclusion must be that the evidence for a macrofaunal community change in the high dose basin is marginal, though it should be noted that there is supporting evidence of biological change from the same parametric analysis carried out on the meiofauna (Warwick et al. 1988).

Turning to the analysis of pollutant levels, sediment PAH concentrations in Basins C, L, M and $\mathrm{H}$ are given in Appendix 1, Table 3, and sediment metal levels in Appendix 1, Table 13. The PAH array was subjected to precisely the same statistical treatment as for the field data, yielding the PCA ordination shown in Fig. 18. The

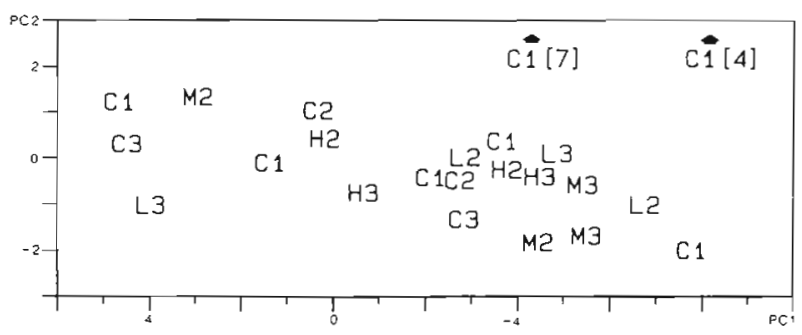

Fig. 18. PCA ordination of sediment levels of selected PAHs from Basins C, L, M and H (Appendix 1, Table 3). Qualifiers 1. 2 and 3 denote sampling dates: initial (16 May), mid-term (13 June) and final ( 7 July) respectively. PAH concentrations were - -transformed and normalised prior to the PCA. The first 2 PCs account for $89 \%$ of the variability

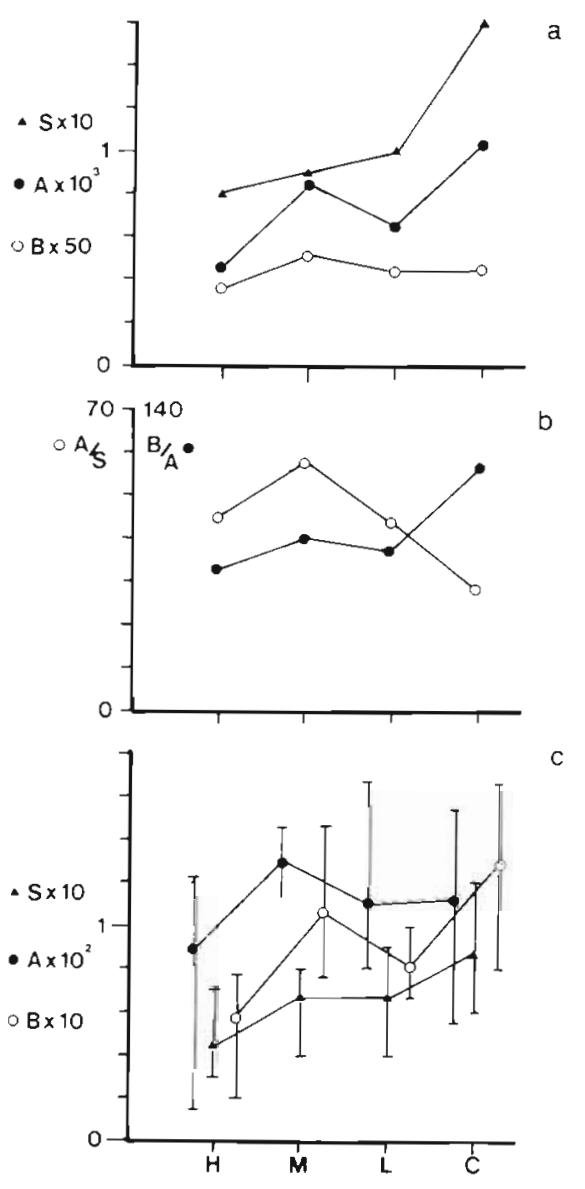

Fig. 19. SAB curves of pooled mesocosm macrofauna data based on whole box samples. (a) Composite data (summation of values across all boxes in each treatment); (b) abundance ratio $(A / S)$ and size ratio $(B / A)$; (c) mean and range of values $S$ : number of taxa, $A$ : total abundance; $B$ : total biomass of all organisms found (see text). Note scale changes between (a) and $(c)$ 


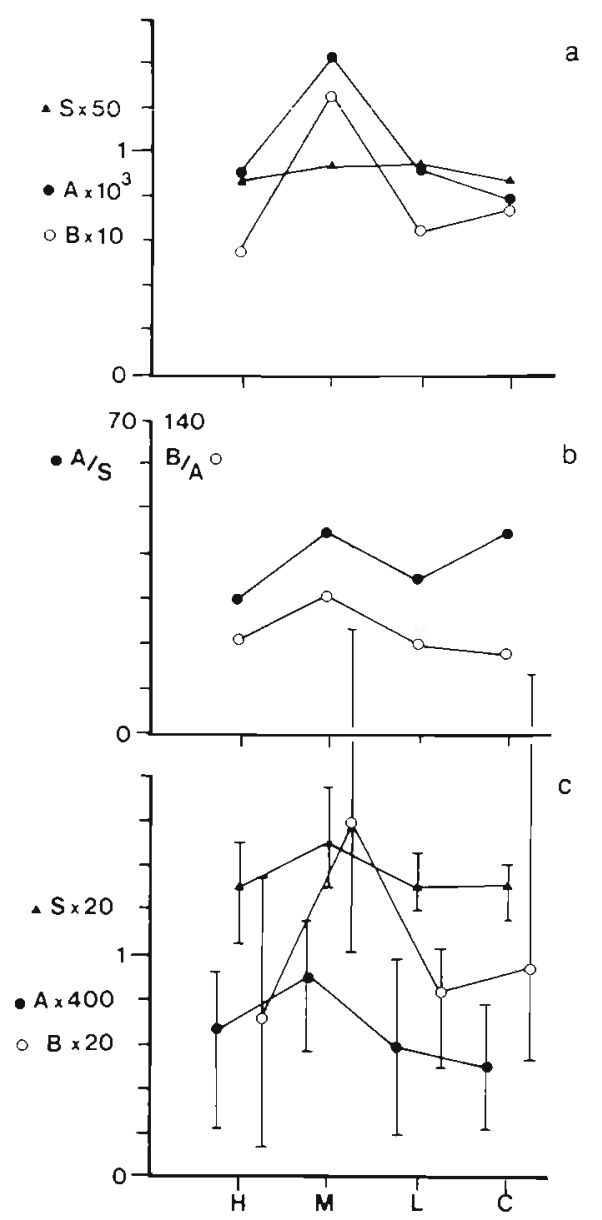

Fig. 20. SAB curves of mesocosm macrofauna data based on individual core samples. (a), (b) and (c) as for Fig. 19

metal data is now univariate ( $\mathrm{Cu}$ was the only metal dosed) and the appropriate statistical treatment is simply a one-way analysis of variance (on square root transformed data again). Both univariate and multivariate tests demonstrate that neither the organic or inorganic contaminants dosed to the basins were taken up by the sediments; it is not possible to reject the hypothesis of 'no differences in sediment concentrations', either between basins or through time.

An assessment of the macrofaunal data from entire box samples was made using $S A B$ curves. With only 4 treatments to compare, the delineation of strong trends is unlikely. However, the comparison suggested a possible difference between the control box and the other 3 treatments (Fig. 19) in that the control box showed higher species numbers and biomass than did the other 3 boxes. Plots of the $B / A$ and $A / S$ ratios followed the pattern characteristic of enrichment gradients (Pearson et al. 1982), where the highest values for $B / A$ were found in the control box and the lowest in the high dose box. However, since not all taxa from the boxes were completely analysed and the intratreat-
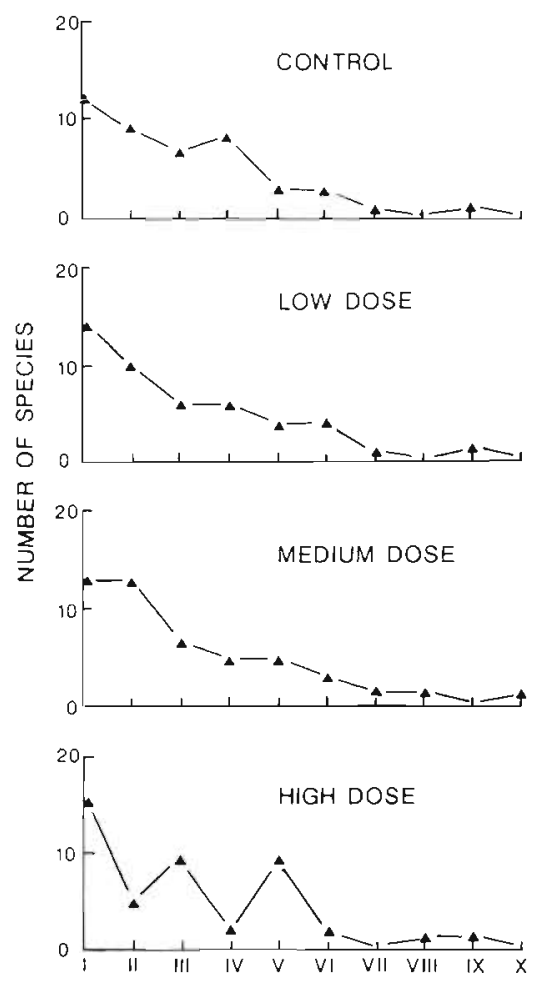

INDIVIDUALS (X2 GEOMETRIC CLASSES)

Fig. 21. Mesocosm macrofauna. Plot of number of species against number of individuals per species in $\times 2$ geometric classes (see legend for Fig. 5)

ment variability was high (Fig. 19C) it was decided that further analysis of this data set was not justified. SAB analysis of the individual core samples from the mesocosm showed no apparent pattern (Fig. 20a). Comparison of the size and abundance ratios revealed no trends (Fig. 20b) and intratreatment variability was high for all 3 variables (Fig. 20c). Neither diversity $\left(H^{\prime}\right)$ nor equitability $(J)$ showed any trend nor was there any apparent difference indicated by Sander's rarefaction index. Thus these techniques did not distinguish any effects of pollutants between treatments.

Analysis of the abundance of individuals among species suggested that the high dose treatment had an uneven distribution of abundance groups (Fig. 21) which in previous studies has been interpreted as being indicative of the effect of moderate organic enrichment (Gray \& Pearson 1982, Pearson et al. 1983). Moreover, an examination of those species contributing to abundance groups with individual numbers between 8 and 63 in the control sample and the high dose sample revealed the presence of many of the same species identified by Pearson et al. (1983) as being particularly responsive to organic enrichment. Four of this group of species Pholoe minuta, Prionospio malmgreni, $P$. cirrifera, Scalibregma inflatum) increased in 
numbers from the control to the high dose treatment and 3 decreased (Ophiura affinis, Mediomastus fragilis and Sosane gracilis). With the exception of $M$. fragilis the data accord with their predicted behaviour based on previous studies. Thus this analysis proved useful not only in identifying a difference between treatments, but provided a means of rapidly identifying those species responding to the environmental change imposed and allowed comparative cross referencing to subsets of species similarly extracted from previous field data sets.

\section{DISCUSSION}

In the results presented above, we have combined what might be termed the 'classical' approach to determining biological effects of pollutants - which relies heavily on the experience and intuition of the investigator - with techniques which attempt to be more objective and can be used by less experienced investigators or in regions of the world where the fauna is poorly known. The classical approach involving the calculation of various indices such as those presented in Table 2, and the identification of species or higher taxa which are indicative of particular pollution effects, e.g. organic enrichment, are undoubtedly very powerful when applied by knowledgeable experts. The various measures which have been applied here are in close agreement with each other and together they define a clear gradient in the level of disturbance across field sites. However, the interpretation of this information remains highly subjective, does not lend itself readily to formal statistical analysis, and has not been clearly documented for use by the inexperienced. For example, by how much does the community have to be dominated by deposit feeders to be indicative of organic enrichment, and how much is this proportion affected by water depth, current speed and sediment type? The experienced investigator would intuitively compensate for these natural 'nuisance' variables in making his assessment of the situation. It is difficult to see how this approach could be documented adequately, except perhaps by the development of computer-based 'expert systems'.

The classical approach involves elements of both the multivariate and univariate methods of data analysis used above, applied in a selective manner and based on a great deal of previous empirical correlation between community attributes and pollution levels. There are many situations in which this approach would not be possible, e.g. the tropics, where there is very little quantitative information on the baseline levels for various indices, or on which species might be regarded as pollution indicators. For these situations a more objective set of protocols needs to be followed. Whilst it would be incorrect to set down hard and fast rules, we believe there is merit in adopting a standard suite of techniques such as that used here.

Initially, it is necessary to establish whether, and to what extent, there are faunistic changes taking place along a supposed or measured pollution gradient, either in space or over time. The multivariate ordination techniques used above gave results rather similar to each other, although MDS and DECORANA had slightly more resolving power than RA and PCA in our study. There are advantages in applying more than one method, since each is based on different assumptions and may give different insights. However, it is important to report all results and so avoid selection biases; it is often the common features of different analyses that point to the most robust conclusions.

Next it is important to establish whether the benthic community at particular sites is showing signs of stress. Leaving aside the various methods associated with the classical approach, $A B C$ plots and plots depicting the distribution of numbers of individuals among species proved useful in our study, although it must be admitted that currently they lack a suitable statistical framework by which the significance of differences between sites can be assessed. Individuals among species plots potentially identify the species which are most indicative of disturbance in the samples (Pearson et al. 1983), which may be useful in geographic regions where the taxonomic identity of such species is not known. In our study, these species of intermediate abundance were not shown to be of major importance in determining the patterns of faunistic similarity between sites, further suggesting that these differences resulted from the effects of natural environmental variables rather than pollution.

Next one needs to establish whether faunistic differences between sites, or measures indicating levels of disturbance, are correlated with measured levels of pollutants (or some estimate of pollutant loading such as distance from the source), or whether they correlate more closely with differences in natural environmental variables which are known to influence community structure, two of the more obvious being water depth and sediment granulometry. We have indicated methods of correlating these variables with both multivariate $2-\mathrm{D}$ ordination configurations and with univariate measures of disturbance; both suggest that water depth, possibly associated with seasonal anoxia at the deeper sites, was the overriding environmental factor controlling community structure in our study, masking any possible pollutant effects.

Such studies can provide very strong correlative evidence of the effect of pollutants on benthic communities, but cannot unequivocally establish a cause- 
and-effect relation. This can only be achieved by experimental manipulations of pollutant levels under controlled conditions either in the field or, as in our study, in laboratory mesocosms. In our study the results were highly equivocal, largely because the pollutants failed to penetrate the sediments over the timescale of the experiment. Although the classical approach provided some indications of nutrient enrichment effects in the high dose boxes, these affects were not shown to be statistically significant, and standard multivariate analyses of the kind used on the field data largely failed to reveal clear differences between treatments. Although useful as a research tool, such experiments are unlikely to play a major role in programmes to monitor the effects of pollution on benthic communities because of the high costs of setting them up and maintaining them. Such studies will therefore usually continue to have strong correlative evidence as their endpoint.

Acknowledgements. We are grateful to John Hall, Roger Carter and Helen Archer for assistance in computing before, during and after the workshop; also, to Brage Rygg for polychaete analyses, to Inger Saanum for assistance in the other taxonomic work and to Andrea Gigg for figure preparation.

\section{LITERATURE CITED}

Bakke, T., Follum, O. A., Moe, K. A., Sørensen, K. (1988). The GEEP Workshop: mesocosm exposures. Mar. Ecol. Prog. Ser. 46: 13-18

Bray, J. R., Curtis, J. T (1957). An ordination of the upland forest communities of Southern Wisconsin. Ecol. Monogr. $27: 325-349$

Buchanan, J. B. (1963). The bottom fauna communities and their sediment relationships off the coast of Northumberland. Oikos 14: 154-175

Clarke, K. R., Green. R. H. (1988). Statistical design and analysis for a 'biological effects' study. Mar Ecol. Prog. Ser. 46: 213-226

Everitt, B. (1974). Cluster analysis. Heinemann, London

Field, J. G., Clarke, K. R., Warwick, R. M. (1982). A practical strategy for analysing multispecies distribution patterns. Mar Ecol. Prog. Ser 8: 37-52

Follum, O. A., Moe, K. A. (1988). The GEEP Workshop: field sampling. Mar. Ecol. Prog. Ser 46:7-12

Gray, J. S., Pearson, T H. (1982) . Objective selection of sensitive species indicative of pollution-induced change in benthic communities. I. Comparative methodology. Mar Ecol. Prog. Ser. 9: 111-119

Harris, R. J. (1975). A primer of multivariate statistics. Academic Press, New York

Heip, C., Warwick, R. M., Carr, M. R., Herman, P. M. J., Huys, R., Smol N., Van Holsbeke, K. (1988). Analysis of commun- ity attributes of the benthic meiofauna of Frierfjord/ Langesundfjord. Mar Ecol. Prog. Ser. 46: 171-180

Hill, M. O. (1973). Reciprocal averaging: an eigenvector method of ordination. J. Ecol. 61: 237-249

Hill, M. O., Gauch, H. G. (1980). Detrended correspondence analysis, an improved ordination technique. Vegetatio 42 : $47-58$

Kruskal, J. B., Wish, M. (1978). Multidimensional scaling. Sage Publications, Beverley Hills, California

Lambshead, P. J. D., Platt, H. M., Shaw, K. M. (1983). The detection of differences among assemblages of marine benthic species based on an assessment of dominance and diversity. J. nat. Hist. 17: 859-874

Pearson, T H., Duncan, G., Nuttal, J. (1982). The Loch Eil Project: population fluctuations in the macrobenthos. J. exp. Mar. Biol. Ecol. 56: 305-321

Pearson, T H., Gray, J. S., Johanessen, P. J. (1983). Objective selection of sensitive species indicative of pollutioninduced change in benthic communities. 2. Data analysis. Mar Ecol. Prog. Ser. 12: 237-255

Pearson, T. H. Rosenberg, R. (1978). Macrobenthic succession in relation to organic enrichment and pollution of the marine environment. Oceanogr mar. Biol. A. Rev. 16: 229-311

Pillai, K. C. S. (1967). Upper percentage points of the largest root of a matrix in multivariate analysis. Biometrika 54 : 189-194

Pimentel, R. A. (1979). Morphometrics; the multivariate analysis of biological data. Kendall/Hunt, Dubuque, Iowa

Rosenberg, R. (1972). Benthic faunal recovery in a Swedish fjord following the closure of a sulphite pulp mill. Oikos 23: $92-108$

Rosenberg, R. (1976). Benthic faunal dynamics during succession following pollution abatement in a Swedish estuary. Oikos 27: 414-427

Roy, S. N. (1953). On a heuristic method of test construction and its use in multivariate analysis. Ann. math. Statist. 24: $220-238$

Rygg, B., Bjerkeng, B., Molvaer, J. (1985). Grenlandsfjordene og Skienselva 1985. Overväkningsrapport nr. 202/85. Norsk Institutt for Vannforskning, Oslo

Rygg, B., Skei, J. (1984). Correlation between pollution load and the diversity of marine soft-bottom fauna communities. In: Proceedings of the international workshop on biological testing of effluents (and related receiving waters). Organisation for Economic Co-operation and Development / US Environmental Protection Agency / Environ. Canada, p. 153-183

Seber, G. A. F. (1984). Multivariate observations. Wiley, New York

Warwick, R. M. (1986). A new method for detecting pollution effects on marine macrobenthic communities. Mar. Biol. 92: $557-562$

Warwick, R. M., Carr, M. R., Clarke, K. R., Gee J. M., Green, R.H. (1988). A mesocosm experiment on the effects of hydrocarbon and copper pollution on a sublittoral softsediment meiobenthic community. Mar Ecol. Prog. Ser. 46: $181-191$

Warwick, R. M., Pearson, T H., Ruswahyuni (1987). Detection of pollution effects on marine macrobenthos: further evaluation of the species abundance/biomass method. Mar. Biol. 95: $193-200$ 